\title{
Orthodontic Comouflage Treatment of Class II Malocclusion in Non-growing Patient - A Cose Report
}

\author{
Dr Lubna Khan,' Dr Hemant Kumar Halwai, ${ }^{2}$ Dr Rajiv Yadav, ${ }^{3}$ Dr Ourvind Jeet Singh Birring ${ }^{4}$ \\ 'Assistant Professor, ${ }^{2}$ Associatet Professor, Dept of Orthodontics, ${ }^{4}$ Assistant Professor, Dept of Conservative Dentistry \& Endodontics \\ College of Dental Surgery, Universal College of Medical Sciences, Bhairahawa, Nepal \\ ${ }^{3}$ Assistant Professor, Dept of Orthodontics, Institute of Medicine, Kathmandu, Nepal
}

\begin{abstract}
The prevalence of skeletal Class II malocclusion is high amongst Asian population. Various treatment modalities have been presented for the treatment of Class II malocclusions in adult patients. We come across many adult patients who desire a costeffective and non-surgical correction and they accept dental camouflage as a treatment option to mask skeletal discrepancy. This case report presents a 26-year-old non-growing female who had a skeletal Class II malocclusion with prognathic maxilla and retrognathic mandible with an overjet of $7 \mathrm{~mm}$, severe crowding, but did not want surgical treatment. We considered the camouflage treatment by extracting upper first premolars. Following the treatment, a satisfactory result was achieved with an acceptable static and functional occlusion, facial profile, smile and lip competence with patient satisfaction.
\end{abstract}

Keywords: Class II malocclusion, orthodontic camouflage

\section{INTRODUCTION}

Over the last decade, increasing number of adults have become aware of orthodontic treatment and are demanding high-quality treatment in shortest possible time with increased efficiency and reduced cost.' Class II malocclusion can be treated by several means according to the characteristics associated with the problem, such as antero-posterior discrepancy, age, patient compliance. ${ }^{2}$ In adolescents, the correction of Class II malocclusion by growth modification is the treatment of choice..$^{3-5}$

In adult patients where growth no longer occurs, dental camouflage by selective removal of permanent teeth and orthognathic surgery are the treatment options. In adults with severe skeletal malocclusion involving deficient mandible; orthognathic surgery is often the possible treatment. However in Class II patients with mild-tomoderate skeletal discrepancies, dental compensation is the treatment of choice. ${ }^{6}$ A recent study showed that the patient satisfaction with camouflage treatment was similar to that achieved with surgical mandibular advancement. ${ }^{7}$ Camouflage usually involves the extraction of premolars. Variations in extraction sequence including upper and lower first or second premolars have been recommended by different authors. ${ }^{8-11}$
Correction of Class II malocclusion in non-growing patients usually requires extraction of four premolars. When the mandibular dental arch is treated without extraction; removal of two maxillary premolars are done accepting a Class II molar relationship. Typically, the first premolars are extracted to resolve anterior malalignment and increased overjet. $^{12}$

The present case report demonstrates the camouflage treatment of an adult Class II malocclusion case with severe crowding in both arches.

\section{CASE REPORT}

A 26 years old female reported to the Department of Orthodontics for orthodontic treatment with the chief complaint of forwardly displaced and crooked upper front teeth and inability to close the lips leading to embarrassment in social gatherings.

Extra-oral examination revealed mesocephalic symmetrical face, convex profile, lip incompetence and an acute nasolabial angle. The patient showed a good range of mandibular movements with no TMJ symptoms.

Intraorally, the patient had severely crowded and proclined maxillary incisors with an overjet of $7 \mathrm{~mm}$, high 
Table 1: Cephalometric record

\begin{tabular}{|c|c|c|c|c|}
\hline & Parameter & Norms & Pre-treatment & Post-treatment \\
\hline \multirow{5}{*}{ Skeletal } & SNA & $82^{\circ}$ & $86^{\circ}$ & $82^{\circ}$ \\
\hline & SNB & $80^{\circ}$ & $78^{\circ}$ & $78^{\circ}$ \\
\hline & ANB & $2^{\circ}$ & $8^{\circ}$ & $4^{\circ}$ \\
\hline & Wits & $-1 \mathrm{~mm}$ & $6 \mathrm{~mm}$ & $2 \mathrm{~mm}$ \\
\hline & GoGn-SN & $32^{\circ}$ & $41^{\circ}$ & $40^{\circ}$ \\
\hline \multirow{4}{*}{ Dental } & UI-SN & $105^{\circ}$ & $118^{\circ}$ & $114^{\circ}$ \\
\hline & UI - NA & $4 \mathrm{~mm} / 22^{\circ}$ & $12 \mathrm{~mm} / 34^{\circ}$ & $8 \mathrm{~mm} / 27^{\circ}$ \\
\hline & LI - NB & $4 \mathrm{~mm} / 25^{\circ}$ & $9 \mathrm{~mm} / 27^{\circ}$ & $9 \mathrm{~mm} / 31^{\circ}$ \\
\hline & IMPA & $90^{\circ}$ & $83^{\circ}$ & $94^{\circ}$ \\
\hline \multirow{2}{*}{ Soft-Tissue } & S/Line-U/L & 0 & $+4 \mathrm{~mm}$ & $+2 \mathrm{~mm}$ \\
\hline & $\mathrm{L} / \mathrm{L}$ & 0 & $+3 \mathrm{~mm}$ & $+3 \mathrm{~mm}$ \\
\hline
\end{tabular}

maxillary canines, severely crowded lower anteriors, missing lower first molars and mesially tipped lower second and third molars. The lower midline was shifted to the right side by $3 \mathrm{~mm}$. The molar and canine relationships have not been mentioned due to missing lower first molars on both sides and bilateral upper high canines (Figure 1).

The cephalometric analysis confirmed skeletal Class ॥ malocclusion due to prognathic maxilla and retrognathic mandible with an ANB $8^{\circ}$, Wits $7 \mathrm{~mm}$, vertical growth pattern, proclined and forwardly placed maxillary incisors (Table 1).

The patient was diagnosed as Class II malocclusion with proclined and severely crowded upper and lower anterior teeth.

\section{Treatment objectives}

1. Relieve crowding

2. Achieve occlusal intercuspation with Class I canine relation

3. Achieve lip competence

4. Develop ideal overjet and overbite

5. Correct the antero-posterior relationship

6. Improve facial profile and esthetics.

\section{Treatment plan}

1. Extraction of maxillary first premolars

2. Leveling and alignment of the arches

3. 2-step retraction of maxillary anterior segment

4. Final consolidation of space and settling of the occlusion.

\section{Treatment mechanics}

The maxillary first premolars were extracted. All first molars were banded and the maxillary and mandibular arches were bonded with $0.018 \times 0.025$ pre-adjusted edgewise brackets. An initial 0.014 inch round thermal nickel titanium (NiTi) archwire was used for levelling and alignment of the arches followed by $0.016 \mathrm{NiTi}$ archwires. Canine retraction was done in the upper arch with light forces applied by the elastomeric chain placed between the canine and molar hooks on 0.016-inch round thermal NiTi wire on both sides for creating space for the alignment of lateral incisors. This was followed by the placement of 0.016 round stainless steel (SS) wire with stop loops placed flushed to the molar tubes for complete canine retraction by sliding mechanics. After canine retraction, $0.016 \times 0.022$ SS wire with closing loops was placed for the retraction of the incisors. Interproximal stripping was performed on the maxillary incisors and additional labial root torque was incorporated in the anterior segment of the wire to correct the inclination of the incisors. Class II elastics were given. Final finishing was done with $0.017 \times 0.025$ SS wires with appropriate torque. Final occlusal settling was done with the help of settling elastics between the upper and lower posterior teeth. The case was debonded in 18 months. A maxillary wrap-around retainer and a mandibular flexible spiral wire (FSW) retainer was given.

\section{Treatment result}

A functional occlusion with Class I canine, well-aligned arches, proper overjet and overbite was achieved. Lip competence and a marked improvement in patient's smile and facial appearance were achieved (Figure 2). 


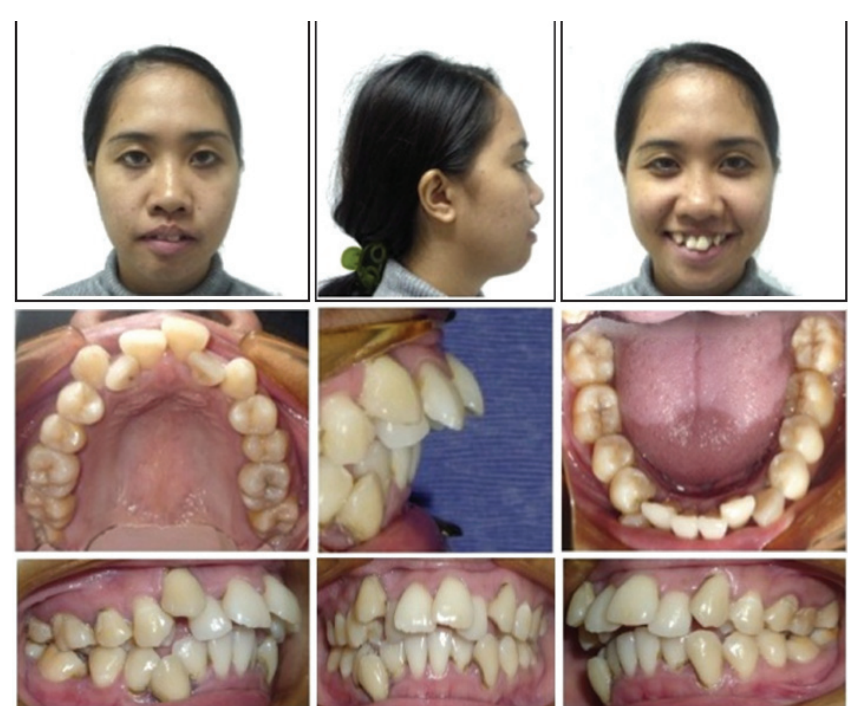

Figure 1: Pre-treatment photographs
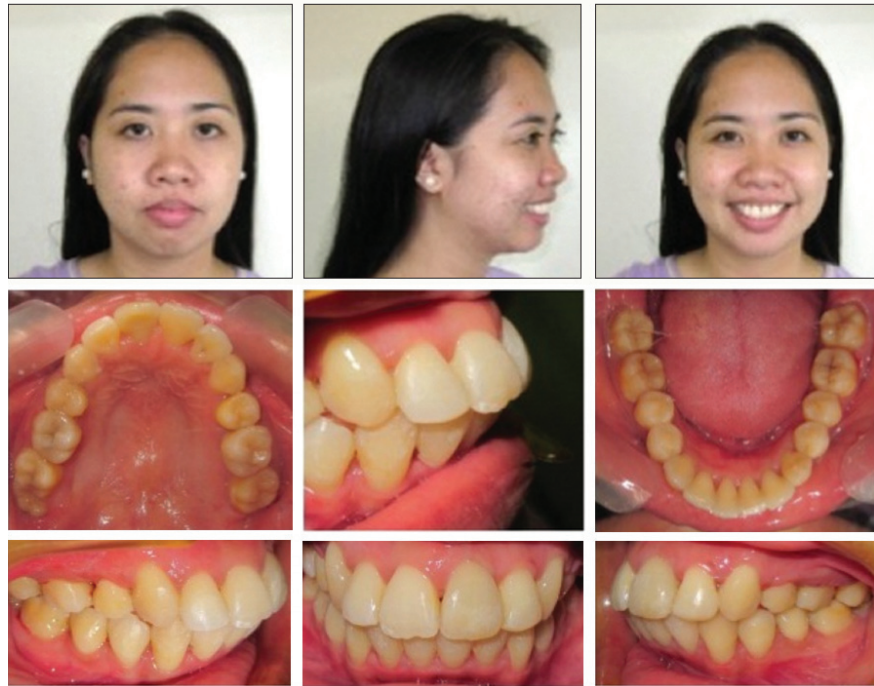

Figure 2: Post-treatment photographs

\section{DISCUSSION}

Class II malocclusion in non-growing patients can be treated in one of the three ways: non-extraction with distalization mechanics, extraction, and a combination of orthodontics and orthognathic surgery. The nonextraction/distalization mechanics unnecessarily prolongs treatment time and results in redundant tooth movements that lead to irreversible root damage and possible adverse periodontal sequelae. 13,14 Dentoalveolar camouflage of milder Class II cases is possible in most instances without surgery. ${ }^{12}$ Moreover, most of the adult patients prefer camouflage treatment over surgical correction due to risk and cost factors associated with the latter.

Treatment for Angle Class II Division 1 malocclusions involve various extraction decisions, such as extraction of four first premolars, two maxillary first premolars plus two mandibular second premolars, two maxillary premolars, ${ }^{15-17}$ and two maxillary premolars plus one mandibular incisor. ${ }^{18}$
A comprehensive extraction strategy should be based on considerations on growth pattern, soft tissue profile, degree of crowding, molar relationship and mid-line discrepancy. ${ }^{19}$ Treatment of adult Class II patient requires careful diagnosis and a treatment plan involving esthetic, occlusal, and functional considerations. ${ }^{20-22}$

In the present case, surgical treatment option was declined by the patient and it was decided to camouflage the skeletal discrepancy by extracting the maxillary premolars and retracting the anterior teeth to improve facial profile and obtain proper functional occlusion. In the mandibular arch the missing first molars led to the decision of nonextraction treatment strategy and utilization of the space obtained from up-righting the second and third molars for relieving the crowding. 


\section{REFERENCES}

1. Khan RS, Horrocks EN. A study of adult orthodontic patients and their treatment. Br J Orthod. 1991; 18(3):183-94.

2. Salzmann JA. Practice of orthodontics. Philadelphia: J. B. Lippincott Company, 1966; p. 701-24.

3. Staley R. Etiology and prevalence of malocclusion, in Textbook of Orthodontics, ed. S. Bishara, W.B. Saunders Co., Philadelphia, 2001, p.83.

4. Baccetti T, Franchi L, MCNamara JA, Tollaro I. Early dentofacial features of Class II malocclusion: A longitudinal study from the deciduous through the mixed dentition. Am J Orthod. 1997; 111:502-9.

5. McNamara JA. Components of Class II malocclusion in children 8-10 years of age. Angle Orthod. 1981: 51:177-202.

6. Uribe F, Nanda. Treatment of Class II, Division 2 Malocclusion in Adults: Biomechanical Considerations. J Clin Orthod. 2003; 11:599-606.

7. Mihalik CA, Proffit WR, Phillips C. Long-term follow-up of Class II adults treated with orthodontic camouflage: A comparison with orthognathic surgery outcomes. Am J Orthod. 2003; 123:266-78.

8. Staggers JA. A comparison of results of second molar and first premolar extraction treatment. Am J Orthod Dentofacial Orthop. 1990: 98:430-6.

9. Luecke PE, Johnston LE. The effect of maxillary first premolar extraction and incisor retraction on mandibular position: testing the central dogma of 'functional orthodontics'. Am J Orthod Dentofacial Orthop. 1992; 101:4-12.

10. Proffit WR, Phillips C, Douvartzidis N. A comparison of outcomes of orthodontic and surgical orthodontic treatment of Class II malocclusion in adults. Am J Orthod Dentofacial Orthop. 1992: 101:556-65.

11. Basciftci FA, Usumez S. Effects of extraction and non-extraction treatment on Class I and Class II subjects. Angle Orthodo. 2003; 73:36-42.

12. deAngelis V. Atypical Orthodontic Treatment of severe Class II malocclusions in the Adult. J Massachusetts Dent Soc. 2008; 57:26-9.

13. Gianelly AA. The bi-dimensional technique: Theory and practice. Bohemia (NY): GAC International, 2002.

14. Chiu PP, MCNamara JA, Franchi L. A comparison of two intraoral molar distalization appliances: distal jet versus pendulum. Am J Orthod. 2005; 128:353-65

15. Brandt S, Safirstein GR. Different extractions for different malocclusions. Am J Orthod. 1975; 68(1):15-41.

16. Weintraub JA, Vig PS, Brown C, Kowalski CJ. The prevalence of orthodontic extractions. Am J Orthod Dentofacial Orthop. 1989; 96(6):4626.

17. DeCastro N. Second premolar extraction in clinical practice. Am J Orthod. 1974; 65(2):115-37.

18. Klein DJ. The mandibular central incisor: An extraction option. Am J Orthod Dentofacial Orthop. 1997; 111 (3):253-9.

19. Ackerman JL, Proffit WR. Soft tissue limitations in orthodontics: treatment planning guidelines. Angle Orthod. 1997; 67(5):327-36.

20. Nanda, R.: Biomechanics and Esthetic Strategies in Clinical Orthodontics, W.B. Saunders Co., Philadelphia, 2009.

21. Kuhlberg A, Glynn E. Treatment planning considerations for adult patients. Dent Clin N Am. 1997; 41:17-28.

22. Nanda, R.: Correction of deep overbite in adults. Dent Clin N Am. 1997; 41:67-88. 